\title{
Effective Means of Reading Control for Improving Innovative Competence of Future Mining Engineers
}

\author{
Sergey Lebedintsev ${ }^{1,}$, Lyubov Fedyanina ${ }^{2}$, and Vyacheslav Gustov ${ }^{1}$ \\ 1. T.F. Gorbachev Kuzbass State Technical University, 650000, 28 Vesennyaya St., Kemerovo, Russia \\ 2. Kemerovo State University, 650043, 6 Krasnaya St., Kemerovo, Russia
}

\begin{abstract}
The current level of development of the mining industry requires the use of innovations in the practice of higher mining education based on the achievements of psychology and pedagogy which allow to achieve optimal results in training mining engineers. Foreign language proficiency is an important component of the professional competence of any specialist. To study the communicative abilities of students, it is necessary to search for new learning technologies in the activation of speech activity. The use of innovative technologies in the process of learning to control foreign language reading is a necessary condition for the intellectual and creative development of students - their innovative competence, which is aimed at the formation of professional knowledge and skills for the most effective achievement of innovative goals of their professional activities. The authors share practical and theoretical experience as well as innovative ideas for the construction and successful application of faceted tests that can help overcome the difficulties taking place in decoding text information.
\end{abstract}

\section{Introduction}

Proficiency in a foreign language or foreign languages becomes an integral part of international cooperation, in this regard, special requirements are made to graduates including not only the presence of high professional qualities, but also the ability to communicate with partners who are representatives of other linguistic communities to take into account not only their cultural identity and linguistic specifics, but also professional activities.

Therefore foreign language teaching at the University should be built in such a way as to interest students offering new methods and development of tasks and exercises including the control of the acquired teaching material. The latter it seems to be well-grounded, because there is undiminishing interest of domestic and foreign researchers offering their solutions for the current, intermediate and final control of learning. In most researches on

\footnotetext{
*Corresponding author: lebsv1965@mail.ru
} 
this subject special attention is paid to test items that check only the level of proficiency in language competence and its single parts.

It's known that along with the generally accepted concept test it is actively used common terms control task, control test, etc. Peter Doye [1] was one of the first researchers who presented his review of various test items ordered by function and form in his work on the basis of the analyzed theoretical sources, in other words, he proposed a typology of the test items which did not lose its practical importance in teaching foreign languages for a long time.

In spite of the large number of works on presented subject matter there are still debatable questions about how to make a test correctly, how many answers it should provide for one question, which sentences it would be better to use in the task definitions (narrative or interrogative), etc. The traditional scheme of constructing a test still has been maintained for a long time: to solve any test item as a rule it is proposed four response options corresponding to the first letters of the alphabet (a, b, c, d) to each initial sentence graphically depicted in Arabic numeral. But, for example, taking into account the specifics of foreign language professional texts containing terminology of a particular industry which is very difficult to learn, higher school students often use the principle "at random" which sometimes corresponds to the correct choice of response. For that matter, students don't pay due regard to either the information extracted from the text or the differentiation of language units.

In our opinion, the most effective instrument of control should be considered facet tests through which the continuous control of the adoption of the material studied by students is realized and students' knowledge to decode information and to analyze carefully language units is evaluated through the developed criteria.

\section{Materials and methods}

The main object of this study is to present a technology constructing facet test items and applying them in reading mining texts with response to decode information cognitively. To achieve these aims it should be based on both the traditional methods that are used quite effectively in teaching and on up-to-date developments of the facet test item system including own ones.

It should be noted that in testing knowledge in reading there is a great probability of copy-off, prompting and other undesirable moments in the presence of a single version of the problem. Therefore, there is a need to develop several options for tasks. To solve this problem we propose to use a faceted technique [2-3].

The term facet originated from French word facette was taken from Biology and means structural-functional unit of compound eye of insects. A facet (a facet feature) is a form that provides a representation of several variants of the same task element.

In comparison with traditional forms of control facet test in reading has some advantages, which are as follows:

1) the facet test using different levels of task difficulty can allow you to measure the level of knowledge and skills quantitatively and the same time qualitatively;

2) the facet test can reflect an objective assessment of the level of students' training and include full coverage of knowledge and skills in control at a certain stage of training;

3 ) the facet test can create favorable conditions for constant control and individual approach in teaching students to reading.

If it acts on the premise that the facet test is one of the forms of educational control so it should meet a number of requirements of which the most important are: validity, reliability, practicality and objectivity $[4,5]$. 
Validity of the test is strictly limited according to the educational micro-purpose, i.e. any test item has a certain focus on testing knowledge and skills of students on a specific topic to be learned.

The reliability of the test implies identical and the same time correct answers of the testees regardless of their level of training and time for the test, that is the results should be unambiguous.

The practicality of the test should be consistent with the training goals that are required when it is performed. If the test items are easy to understand, do not require additional formulation on the part of the teacher and the system of fixing the selected responses is simple for the testee, then such a test can be considered as practical one. The practicality of the test can also include the minimum amount of spent time and mental students' efforts to analyze the technique of performing items that do not require special training.

The test objectivity is its adaptability to an objective quantitative assessment of the results of its implementation. Quantitative expression of the quality of test performance should be based on carefully developed system of standards of learning. It should be taken into account that the test structure could provide a relatively simple calculation of all correct and incorrect responses of testee.

Application of facet tests in teaching to reading is determined by the structure of students' learning process. At the present time the students' activity is conventionally divided into four stages according to their learning levels of teaching material content [6]:

1) understanding;

2) memorization;

3) application of learning to known rules;

4) application of learning in the new conditions.

At the first stage the student gets acquainted with new material, learns the connection of the new material with one already known. Then he assimilates the material so that he is able to reproduce the received information. At the third stage the student can apply the acquired knowledge to solve language problems, which condition directly indicates what rules should be used to solve them. The fourth stage of mastering the educational material is characterized by the fact that the student is able to apply the available information to solve creative non-standard tasks.

It follows from this that when developing faceted test it is necessary to take into account these requirements and strictly follow a certain algorithm.

The algorithm for developing reading items using faceted technology consists of a sequence of the following actions:

1) to definite unit or topic of curriculum;

2) to select a content of item;

3) to select changeable elements (facet-elements);

4) to select common words;

5) to build the structure of the item using the obtained facet-elements and common words.

Let's consider the algorithm of developing facet items in more detail. At the initial stage one must select a part of the training course.

Then one should determine the topic of the selected part of the training course.

Next one should denote the set of items that are similar in their construction and appropriate to the selected topic.

Then one should select the variable facet-elements in the item.

After that it is necessary to highlight the common elements of the item called connecting words.

Next step is to use the obtained faceted-elements and connecting words, to write the faceted structure of the item and to list all the values of the faceted-elements. 


\section{Results and discussion}

Traditionally, test item forms are divided into two groups according to their method and structure of the response: 1) type of the items with a selective response; 2) type of the items with a free constructed response.

Type of the items with selective response includes 1) the items with true-false response; 2) the items with one choice of a correct response; 3 ) items with multiple choice of correct responses; 4) the items for rearrangement; 5) the items for matching.

The second type of items includes the following forms: 1) the items with short response; 2) the items with detailed response.

Long-term observations show that postsecondary foreign language teachers apply mainly single-type test items with selective response in their practice to teaching reading in running control. Test items with one choice of response are used very often and test items with two or more correct responses are used very seldom. The total amount of these items can range from $75 \%$ to $100 \%$ in the test structure. These test items got such widespread using due to both their easiness in constructing (compared with other test forms) and the procedure in quick calculation of the students' assessment results [7].

In addition to the advantages pointed above these items have one drawback which has a negative impact on the objectivity of testing results and performance score of students in the process of control - it is a possibility to guess randomly the correct answers. This problem does not fully meet one of the control requirements to correspond to certain quality characteristics - to the reliability of control by which is understood as obtaining nonrandom but logical results in testing.

For example, if the item with a selective response contains only two elements of response where one of them is correct, so the probability of random guessing the correct response will be $50 \%$ in the test item. If the number of distractors increase by two or three elements in the test item with the choice of one correct response, so in this case, random guessing the correct response will be reduced to $33.3 \%-25 \%$ respectively.

Consequently, the quality of the content of closed-type test items depends on the number of distractors, the more distractors there are in the item, the less there is a probability to guess the correct response at random.

While using a large number of distractors, the developer will need more time to construct the test items with a selective type of response. At the same time, while constructing a task, there is a problem of careful selection of distractors, so that they help students in the process of fulfilling the test.

The development of faceted forms and its application for reading control helps to eliminate the shortcomings noted above.

A facet is a form that provides a representation of several variants of the same element of the test content. Each facet which is distinguished by both-way curly brackets contains the uniformity of the values of the given classification feature, i.e. facet elements must belong to the same enlarged unit of knowledge.

This means that the principle of variability of the test item content is used in the development of items of the faceted form which allows you to develop several variants of tasks in one test item, i.e. individual tasks are combined into one so that the most of students' answers were different. It turns out that the tasks and the responses are different, but checking theme is one and the same. Thus, the variability of the content of each test task excludes the possibility of cheating and random guessing the correct response; thereby it contributes to an objective assessment of the results of items done by students. These items, thanks to their active use, can significantly improve the learning process both at practical classes and in independent work. 
In order to understand better the variability of the content of faceted tests, let's look at a few examples of test items which were developed by us and now are successfully applied in practice.

Here is a small example of a faceted test item with one-choice correct response.

$\{1\}$ Lignite

a) from 60 to $65 \%$

$\{2\}$ Anthracite contains b) from 60 to $75 \%$

$\{3\}$ Brown coal c) from $75 \%$ to $90 \%$

$\{4\}$ Bituminous coal $\quad$ d) more than $90 \%$

This facet contains four variants of tasks (they are marked with curly brackets) and four variants of responses. Variants of responses of each of the tasks are combined into one group according to a certain characteristic. One student can get one of four options in this facet item.

It should be noted that the principle of a differentiated approach to learning is observed with the use of faceted forms, since the content variability of such items allows a large number of students to perform them simultaneously in one place without breaking the principle of equality.

The number of variants of tasks can reach a large number in one facet. For example:

The rock like $\{$ clay\}, \{gravel\}, \{coal\}, \{granite\}, \{limestone $\},\{$ sand $\},\{$ siltstone $\}$, $\{$ quartz $\}$, peat $\},\{$ sandstone $\underline{\text { is }}$ a) loose one.

b) hard

The composition of tasks is based here on the principle of contradiction or opposition: one response indicates some sign and the second one denies this sign.

It follows from the given example that this faceted task contains ten variants of tasks that can cover ten students at the same time. In this case, it will be spent much less time for fulfilling the task and the number of students' responses will be many times as much.

The number of facets depends on item content. Maximum possible number of the task variants is linked with multiplication the number of task-elements in all facets. For example, let's take one facet test intended for control reading mining texts with three task variants:

1. Read the text "Composition of the Coal" to fulfill the facet test given below:

Composition of the Coal

Liptobiolites occur in the Devonian seams in the Barzassky region. These coals are built up by cutinite developed from a thick plant cuticle. In their outward aspects they look like slabby-foliated coals easily splitting into flexible laminae (the Barzassky matting). Sclerotinitic liptobiolite has been revealed as an interlayer $0.8 \mathrm{~m}$ thick.

Sapropelites occur as interbeds $5-60 \mathrm{~cm}$ thick in the humic coal seams of the Mazurovskaya suites. They usually include humus and sapropelites with algae.

1.1. Choose one of the variants of facet task elements given below to find true responses in the test. (After reading the text by students a teacher gives Student 1, for example, one of the facet task elements $\{1.1 .1\}$. Student must find true responses that belong to the facet task elements $\{1.1 .1\}$ in the test. True responses are shown here to analyse better this example.)

$\begin{array}{lll}\text { Student } & \text { Facet task elements } & \text { True Responses } \\ \text { 1. } & \{1.1 .1\} & \mathrm{a} / \mathrm{a} / \mathrm{b} / \mathrm{b} \\ 2 . & \{1.1 .2\} & \mathrm{a} / \mathrm{a} / \mathrm{b} / \mathrm{a} \\ 3 . & \{1.2 .1\} & \mathrm{a} / \mathrm{b} / \mathrm{a} / \mathrm{b} \\ 4 . & \{1.2 .2\} & \mathrm{a} / \mathrm{b} / \mathrm{a} / \mathrm{a} \\ 5 . & \{2.1 .1\} & \mathrm{b} / \mathrm{b} / \mathrm{a} / \mathrm{a} \\ 6 . & \{2.1 .2\} & \mathrm{b} / \mathrm{b} / \mathrm{a} / \mathrm{b} \\ 7 . & \{2.2 .1\} & \mathrm{b} / \mathrm{a} / \mathrm{b} / \mathrm{a} \\ 8 . & \{2.2 .2\} & \mathrm{b} / \mathrm{a} / \mathrm{b} / \mathrm{b}\end{array}$


The chosen variant of task elements $\{1.1 .1\}$ in the facet test and true elements of responses $(\mathrm{a} / \mathrm{a} / \mathrm{b} / \mathrm{b})$ are italicized here.
$\{1\}$ Liptobiolites
having
a) an interlayer $0.8 \mathrm{~m}$ thick
$\{2\}$ Sapropelites
b) interbeds $5-60 \mathrm{~cm}$ thick
$\{1\}$ occur
in the
a) Devonian seams
a) of the Mazurovskaya suites
$\{2\}$ don't occur
b) humic coal seams
b) in the Barzassky region

because they $\{1\}$ are a) a composition of humus and sapropelites with algae.

$\{2\}$ aren't b) slabby-foliated coals easily splitting into flexible laminae.

Thus we have three facets with two elements in the test that make it possible to develop eight variants of items inside one facet test. It can be reached by multiplication the number of elements in each facet: $2 \times 2 \times 2=8$.

This effect is achieved due to the compact structure of the faceted task which in turn reflects the brevity of the task content with an enlarged didactic unit of knowledge. It is undoubtedly the main advantage over traditional forms of closed-type test items.

Assessment of the content of the facet test item can be produced in score. One score is given for each correct response, for the wrong one -0 scores.

It should be noted that an additional measure of the difficulty of the task in this test is 0.5 score for each correct response in the task content from the facet with negative variant as it is quite difficult from the point of view of psychology to give an answer to negative statements.

$\begin{array}{llll}\begin{array}{l}\text { Student } \\ 1 .\end{array} & \begin{array}{l}\text { Facet task elements } \\ \{1.1 .1\}\end{array} & \begin{array}{l}\text { True Responses } \\ \mathrm{a} / \mathrm{a} / \mathrm{b} / \mathrm{b}\end{array} & \begin{array}{l}\text { Score } \\ (0)+1+1+1+1=4\end{array} \\ 2 . & \{1.1 .2\} & \mathrm{a} / \mathrm{a} / \mathrm{b} / \mathrm{a} & (0.5)+1+1+1+1=4.5 \\ 3 . & \{1.2 .1\} & \mathrm{a} / \mathrm{b} / \mathrm{a} / \mathrm{b} & (0.5)+1+1+1+1=4.5 \\ 4 . & \{1.2 .2\} & \mathrm{a} / \mathrm{b} / \mathrm{a} / \mathrm{a} & (0.5+0.5)+1+1+1+1=5 \\ 5 . & \{2.1 .1\} & \mathrm{b} / \mathrm{b} / \mathrm{a} / \mathrm{a} & (0)+1+1+1+1=4 \\ 6 . & \{2.1 .2\} & \mathrm{b} / \mathrm{b} / \mathrm{a} / \mathrm{b} & (0.5)+1+1+1+1=4.5 \\ 7 . & \{2.2 .1\} & \mathrm{b} / \mathrm{a} / \mathrm{b} / \mathrm{a} & (0.5)+1+1+1+1=4.5 \\ 8 . & \{2.2 .2\} & \mathrm{b} / \mathrm{a} / \mathrm{b} / \mathrm{b} & (0.5+0.5)+1+1+1+1=5\end{array}$

You can also apply the facet principle to open-type items where you want to complete the text or missing information with the correct response.

Here is an example of an open-type faceted item with a short answer assuming to fill the gap with the missing word which can be any part of speech (in this case, the numeral):
$\{1\}$ The Don Polytechnic Institute
1)
\{2\} The Mining Institute in Kemerovo
2)
$\{3\}$ The Mining Institute in Yekaterinburg was founded in
$\{4\}$ The Moscow Mining Academy
$\{5\}$ The Technological Institute in Tomsk
5)

The following example is an open-type faceted item with a detailed response which has no restrictions on the content and form of the response, but the formulation of such an item assumes the presence of a standard response. This type of items allows you to test and evaluate the students' ability to express their thoughts in a logical sequence on a particular topic, for example, on topic "The Great Russian Scientists in Mining".

$\{1\}$ I. M. Gubkin

$\{2\}$ A. Y. Fersman

A great contribution to mining was made by
\{3\} A. P. Karpinsky

\{4\} A. M. Terpigorev

$\{5\}$ M. V. Lomonosov

(Write 5 sentences to the chosen point)
1)

2)

3)

4)

5)
-

-

_. 
The faceted test items as well as traditional ones can be applied to all levels of the text organization in control of the intensive reading [8-9]: 1) "to a pre-textual level which purpose is: to control the formation of skills and abilities of a mechanism of probabilistic forecasting according to the content of the text; to motivate students with information to be offered; 2) to a text level - to control the formation of skills and abilities according to the meaning content of the text; 3) to a post-textual level - to control a comprehension of the meaning content of the read text" [10].

Let's consider an example of the facet test item form developing according to their levels of the text organization on basis of the text "Sedimentary Rocks" that is intended for students studying mining. The purpose is a work on the professional-oriented text to form at students their skills and abilities in running control of intensive reading. Some tasks are abridged in form.

I. Usage of facet test items at the pre-textual level:

I.I. Find the following words and word combinations in your dictionary and memorize them to do vocabulary crossword test 1 :

I.II. Test yourself! Do vocabulary crossword test 1 .

I.III. Try to guess and find the Russian translations of the following English terms used in geology. Choose the true variant from the given elements to compose the sentence.

1) The geological term
$\{1\}$ a clay $\{2\}$ a glacier
$\{3\}$ a rock
a) kley
a) lyod
a) kachanie
$\{4\}$ a layer means in Russian
b) glina
b) sneg
c) tina
c) lednik
b) gornaya poroda
a) ryad
$\begin{array}{ll}\text { d) gryaz } & \text { d) aisberg }\end{array}$
c) podvodnyi kamen
b) plast
d) dragotsennyi kamen
c) razrez
d) plyonka

II. Usage of facet test items at the textual level: the text.

II.I. Read the text "Sedimentary Rocks" attentively to fulfill the facet test given below

\section{Sedimentary Rocks}

Sediments are formed at or very near the surface of the Earth by the action of heat, water (rivers, glaciers, seas and lakes) and organisms. Most sedimentary rocks have originated by sedimentation. They are layered or stratified. Sediments are formed at or very near the surface of the Earth by the action of heat, water (rivers, glaciers, seas and lakes) and organisms.

Sedimentary rocks can be formed by the mechanical action of water, wind, frost and organic decay. Such sediments as gravel, sand and clay can be transformed into conglomerates, sandstones and clay schists as a result of the accumulation of materials achieved by the destructive mechanical action of water and wind. Mechanical sediments can be unconsolidated and consolidated. For example, gravel, sand and clay form the group of unconsolidated mechanical sediments, because they consist of loose uncemented particles (grains).

Consolidated rocks are very similar to the loose sediments whose particles are firmly cemented to one another by some substance. The usual cementing substances are sand, clay, calcium carbonate and others. Thus sandstones are consolidated rocks composed of round or angular sand grains, more or less firmly consolidated.

On the other hand, chemical sediments are the result of deposits or accumulations of substances achieved by the destructive chemical action of water. The minerals such as rock salt, gypsum and others are formed through sedimentation of mineral substances that are dissolved in water.

Sediments can also be formed by the decay of the remains of organisms; by the accumulation of plant relics. They are called organic sediments. Limestones, peat, coal, mineral oil and other sediments may serve as an example of organic sediments. 
II.II. Choose one of the variants of facet task elements (FTE) to find true responses in the test.

$\begin{array}{lllllc}\text { Student } & \text { FTE } & \text { Student } & \text { FTE } & \text { Student } & \text { FTE } \\ 1 . & \{1.1 .1\} & 5 . & \{2.1 .1\} & 9 . & \{3.1 .1\} \\ 2 . & \{1.1 .2\} & 6 . & \{2.1 .2\} & 10 . & \{3.1 .2\} \\ 3 . & \{1.2 .1\} & 7 . & \{2.2 .1\} & 11 . & \{3.2 .1\} \\ 4 . & \{1.2 .2\} & 8 . & \{2.2 .2\} & 12 . & \{3.2 .2\}\end{array}$
1. $\{1\}$ Mechanical
$\{1\}$ are formed
$\{2\}$ Chemical
sediments $\{2\}$ aren't formed by mechanical
$\{3\}$ Organic

\author{
action of a) frost \\ b) wind \\ $\underline{\text { and }}$ \\ c) water \\ d) organic decay
}
$\{1\}$ include
a) coal.
$\{2\}$ don't include
b) peat.
c) clay.
d) sand.
e) gravel.
f) gypsum.
g) rock salt.
h) sandstones.
i) mineral oil.

III. Usage of facet test items at the post-textual level:

III.I. Write a short report. Find differences between each sediments.

1. Differences between $\{1\}$ chemical

$$
\{2\} \text { organic sediments and }
$$

mechanical sediments with $\{1\}$ unconsolidated particles

are that: $\{1\}\{1\}$

$\{2\}$ consolidated particles

$\{1\}\{2\}$

$\{2\}\{1\}$

$\{2\}\{2\}$

(Write 6-8 sentences to each facet couple)

\section{Conclusion}

In conclusion, the following should be mentioned:

1. Facet test items in reading are multifunctional tasks with a complex structure and content covering a large amount of program topics. It is also a way of generalization and diagnostics of knowledge, a means of learning individualization and differentiation.

2. Today the development and application of the facet test item system in control reading contributes to a more effective and qualitative formation of foreign-language professional communicative competence of students studying mining.

3. Using the facet test items, in our opinion, increases a control efficiency of the students' learning outcomes level and has more advantages over traditional test item forms.

4. The use of facet test items in working on mining texts showed that the problem of random guessing or cheating responses is almost eliminated. 


\section{References}

1. P. Doye, Typologie der Testaufgaben fuer den Unterricht Deutsch als Fremdsprache (Druckhaus Langenscheidt, Berlin, 1992)

2. M. Rahimi, The Reading Matrix, 7:1, 151-165 (2007)

3. H. Sh. Ahmadi, Y. Ozek, E. Demirel, English Language and Literature Studies, 2:2, 11-19 (2012)

4. G. Fulcher, Fr. Davidson, Language Testing and Assessment: An advanced resource book (Routledge, London2007)

5. A. J. Lawson. Testing the TOEIC: Practicality, Reliability and Validity in the Test of English for International Communication (University of Birmingham, Birmingham, 2008)

6. B. S. Bloom, Taxonomy of Educational Objectives: The Classification of Educational Goals (Cognitive Domain, New York, 1956)

7. L. F. Bachman, Fundamental Considerations in Language Testing (Oxford University Press, Oxford, 1995)

8. H. S. Alyousef, The Reading Matrix, 5:2, 149 (2005)

9. V. Škudienè, Studies about Languages, 2, 94-98 (2002)

10. L. Fedyanina, S. Lebedintsev, V. Gustov, E3S Web Conf., 41, 04042 (2018) 